УДК 624.953

\title{
ОПРЕДЕЛЕНИЕ ДЕФОРМАЦИЙ СТАЛЬНОГО ВЕРТИКАЛЬНОГО ЦИЛИНДРИЧЕСКОГО РЕЗЕРВУАРА ОБЪЕМОМ V=10000 М³ ДЛЯ НЕФТИ С ПРИМЕНЕНИЕМНАЗЕМНОГО ЛАЗЕРНОГО СКАНИРОВАНИЯ
}

\author{
Епифанова Екатерина Александровна, \\ epifanovaea@tpu.ru \\ Национальный исследовательский Томский политехнический университет, \\ Россия, 634050, г. Томск, пр. Ленина, 30.
}

\begin{abstract}
Актуальность темы обусловлена необходимостью разработки новых подходов к оценке и прогнозу конструктивных изменений в пространстве ответственных инженерных сооружений. Решение этой задачи связано с большим количеством неопределенных факторов, таких как неполнота лабораторных данных свойств материалов, а также полевых динамических и статических испытаний подобных сооружений, нехватка аналитической информации и исследований мониторинга. $B$ статье проведен анализ результатов полевых исследований десрормаций стального вертикального цилиндрического резервуара объемом $V=10000$ м $^{3}$ для хранения товарной и некондиционной нефрти и сопоставление с численным анализом его напряженнодеформированного состояния.

Целью исследования является анализ данных по фактической деформации объекта, полученных в результате наземного лазерного сканирования, и оценки его напряженно-деформированного состояния.

Объект: изменение напряженно-десрормированного состояния стального вертикального резервуара объемом $V=10000$ м $^{3}$ для хранения товарной и некондиционной нефти, расположенного на площадке УПН и ГТЭС Сузунского месторождения ООО «РНВанкор».

Методика. Исходными данными для моделирования поведения сооружения послужили материалы наземного лазерного сканирования обследованного участка. Напряженно-десоормированное состояние сооружения было исследовано при помощи программного комплекса на базе метода конечных элементов. Для оценки изменения пространственно-координатного положения и создания идентичной трехмерной модели объекта исследования применялась технология лазерного сканирования. Сканирование объекта производилось наземным лазерным сканером Leica Scanstation C10, далее массив точек обрабатывался 8 программном комплексе Leica Cyclone 8.0, определение деформаций резервуара проводилось в программе 3D Reshaper, для анализа напряженно деформированного состояния изучаемого объекта использовался ANSYS.
\end{abstract}

Результаты. Оценено напряженно-дефрормированное состояние резервуара. Создана цифрровая расчетная модель. Проведено сравнение результатов моделирования с положением конструкций в пространстве, полученном при лазерном сканировании.

Ключевые слова:

Лазерное сканирование, моделирование, деформации, напряженно-деформированное состояние, метод конечных элементов.

\section{Введение}

Важность наблюдений за осадками ответственных инженерных сооружений в эксплуатационный период обусловлена, прежде всего, тем, что анализ результатов наблюдений позволяет дать правильную оценку их технического состояния. Анализ накопленного материала натурных наблюдений позволяет вносить коррективы в теоретические решения, повышая надежность прогноза протекания деформаций во времени. Объективная оценка технического состояния сооружения может быть получена при взаимном рассмотрении нескольких методик наблюдения одновременно: определение фактической геометрии объекта и метода конечных элементов (МКЭ).

В качестве объекта для проведения технического контроля был выбран стальной вертикальный цилиндрический резервуар объемом $\mathrm{V}=10000 \mathrm{M}^{3}$ для хранения товарной и некондиционной нефти, расположенный на площадке УПН и ГТЭС Сузунского месторождения, которое находится в Таймырском Долгано-Ненецком муниципальном районе Красноярского края (рис. 1).

\section{Характеристика природных условий}

Административно район работ находится в Таймырском Долгано-Ненецком муниципальном районе Красноярского края на территории Сузунского ме- сторождения. Расстояние от Игарки до месторождения 130 км (рис. 1), от Дудинки - 160 км, от Нового Уренгоя - 200 км, от Красноярска - 1700 км.

По физико-географическому положению в региональном плане район работ расположен в северовосточной части Западно-Сибирской низменности.

Район представляет собой низменную полого холмистую равнину со средними абсолютными отметками высоты местности $60 \ldots 80$ м над уровнем моря, расположенную в бассейне реки Соленая, принадлежащую Енисейскому речному бассейну.

Водные объекты на территории обследуемого участка представлены верхними звеньями гидрографической сети реки Соленая, к которым относятся небольшие притоки, ручьи, лога, овраги.

Реки характерно равнинные с неярко выраженными, местами обильно заболоченными долинами, плоскими, часто заболоченными водоразделами. Реки отличаются спокойным течением и высокой степенью извилистости. Суровый климат способствует длительному ледоставу (октябрь-май) и отсутствию стока в зимний период на малых реках.

Наиболее широкое распространение имеют термокарстовые озёра, образовавшиеся в результате изменения термических условий мёрзлых грунтов, а также вытаивания подземных льдов, сопутствующие про- 
садками поверхности земли и формированием отрицательных форм рельефа. Они обычно отличаются небольшими размерами и округлыми формами, приурочены в основном к заболоченным поймам рек и плоским водоразделам. Хотя надо отметить наличие в районе исследований и достаточно крупных озер, достигающих по площади нескольких квадратных километров (оз. Бол. Советское) и глубиной до 30 м.

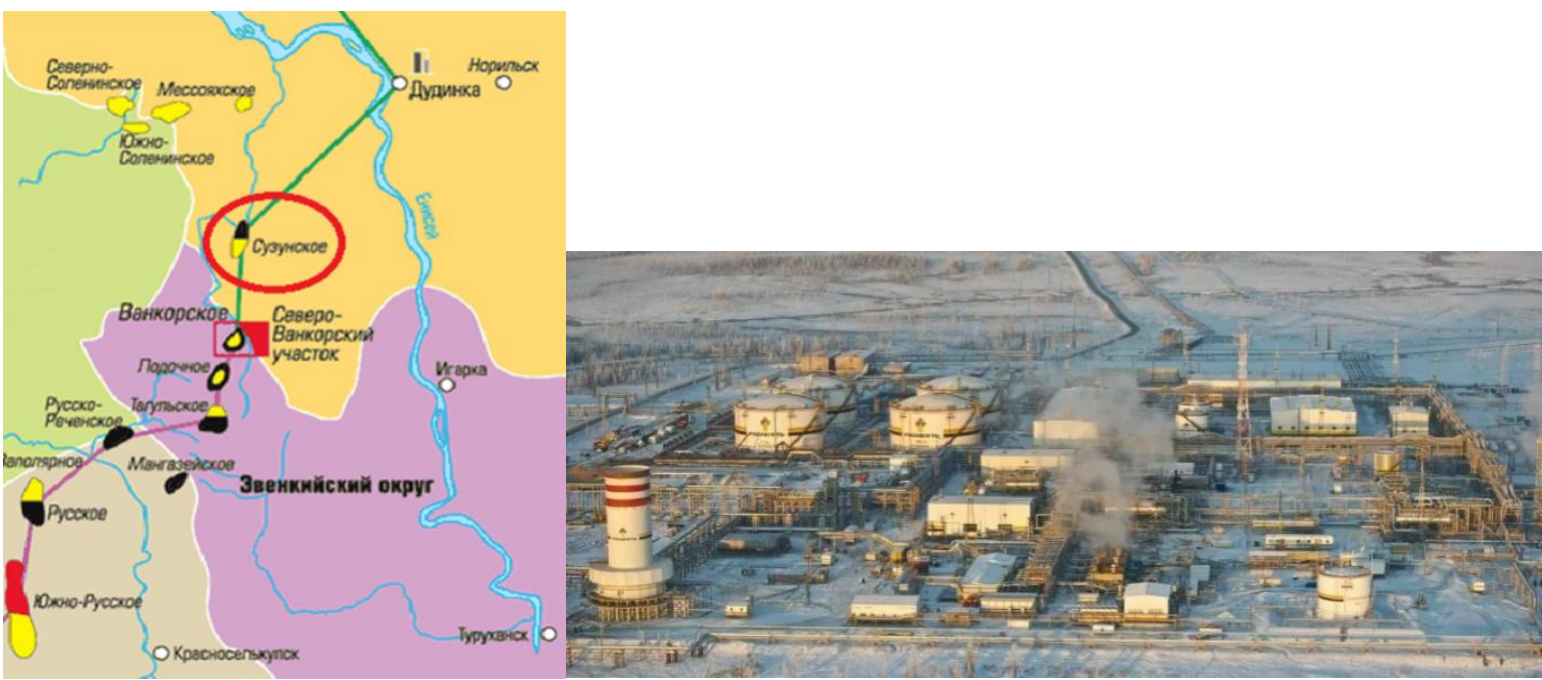

Pис. 1. Сузунское месторождение, район работ обозначен красным контуром, масштаб 1:100000

Fig. 1. Suzunskoe field, the study area - red outline, scale 1:100000

Рельеф территории в его современном виде сформировался в результате процессов морской и ледниковой аккумуляции.

Ледниковая аккумуляция сформировала на существовавшем морском цоколе комплекс форм рельефа ледникового и водно-ледникового происхождения.

Ледниковый тип характеризуется развитием холмисто-грядового рельефа основной морены и озернохолмистого рельефа краевых образований. Характерным морфологическим признаком этого рельефа является обилие озер различной величины и конфигурации, расположенных в понижениях между беспорядочно разбросанными холмами. Развитие озерных котловин происходит под влиянием термокарстовых процессов. Широко развита заболоченность.

Водно-ледниковый тип рельефа представляет собой зандровую равнину с плоской слабонаклонной поверхностью. Волнистый характер поверхности обусловлен чередованием слабовыраженных водоразделов с пологими плохо выраженными склонами и ложбинами стока.

В современную эпоху основными рельефообразующими процессами являются продолжающиеся эрозионно-аккумулятивная речная деятельность и денудация. Существенным фактором рельефоообразования является комплекс процессов, связанных с мерзлотой. Криогенные процессы представлены в виде полигональных грунтов, бугров пучения и тундровых медальонов.

В ландшафтном отношении район располагается в пределах южной субарктической кустарниковой тундры. Высота кустарника, произрастающего по долинам рек и вокруг озер, достигает 2-3 м.

Климат района субарктический. Отрицательная среднемесячная температура воздуха держится в течение 8-9 месяцев. Средняя температура января со- ставляет минус $28{ }^{\circ} \mathrm{C}$. Среднегодовая температура воздуха составляет $-10,1^{\circ} \mathrm{C}$. Лето короткое и холодное. Самый теплый месяц лета - июль, имеет среднюю температуру $+12,3{ }^{\circ} \mathrm{C}$. Средние месячные скорости ветра превышают $5 \mathrm{~m} / \mathrm{c}$, в целом за год средняя скорость составляет 6 м/с. Наибольшие скорости ветра относятся к осенне-зимнему периоду и достигают в октябре $6,4 \mathrm{~m} / \mathrm{c}$. Среднегодовое количество осадков колеблется в пределах 200-250 мм. Снежный покров устанавливается в середине октября, а сходит к концу июня. Реки замерзают в конце сентября - начале октября, а вскрываются в первой половине июня.

В зимнее время преобладают южные ветры. Летом, определяемые влиянием направленности береговой линии со стороны Баренцова и Карского морей, господствуют ветры северных направлений, наибольшую повторяемость имеют северо-восточные ветры. За счет того, что здесь располагается барическая ложбина, простирающаяся от Исландского минимума, в этом районе зимой отмечается усиление циклонической деятельности.

В холодный период года (с октября по апрель-май) проявляется воздействие барических областей, устанавливающихся над северной частью Атлантического океана. В связи с этим зимой, продолжительность которой достигает восьми месяцев, преобладают западные и юго-западные воздушные течения. Они представляют собой поток относительно тёплого воздуха, формирующегося над европейским континенTOM.

С распространением на континент относительно тёплых и насыщенных влагой воздушных масс связано установление облачной погоды, выпадение снега, повышение отрицательной температуры воздуха и малое количество солнечной радиации (21 ккал/см ${ }^{2}$ в год). 
В результате преобладающего северного вторжения арктических масс холодного и сухого воздуха континентального типа в летний период над рассматриваемой территорией устанавливается относительно малооблачная погода антициклонального типа с резким понижением температуры воздуха. В общем для района исследования характерна высокая степень изменения направлений воздушных течений, чем обуславливается неустойчивость погоды в течение всего года.

Исследуемая территория расположена севернее Полярного круга, в области сплошного распространения многолетнемерзлых пород. Исключение могут составлять участки, приуроченные к таликовым зонам под крупными реками и под крупными озерными котловинами.

\section{Наземное лазерное сканирование объекта}

Для измерений использовался наземный лазерный сканер Leica C10, удовлетворяющий требованиям проекта к точности измерений. Для охвата всей поверхности резервуара съемка выполнялась с нескольких позиций на расстоянии до 25 м от РВС (Резервуар Вертикальный Стальной), с шагом точек от 2 до 4 мм. Результаты сканирования объединялись в специализированной программе Leica Cyclone, где проводилась проверка на отсутствие ошибок съемки для получения максимально точного результата модели сканирования РВС. Данная объединённая точечная модель является исходной для определения деформаций РВС.

Резервуар имеет стационарную сферическую крышу, стенку рулонной сборки, изготовленную в виде четырех полотнищ, которые доставлены к месту строительства свернутыми в рулоны. Краткая характеристика объекта технической экспертизы приведена в табл. 1.

Процесс контроля деформаций резервуара условно делится на два этапа: 1) полевые работы - получение первоначальных сырых данных, геометрических параметров исследуемого объекта в виде облака точек

(рис. 2); 2) камеральные работы - обработка полученной информации в результате полевых работ.

$3 \mathrm{D}$ сканирование с внешней и внутренней сторон резервуара было выполнено с целью анализа состояния и положения до начала его эксплуатации, с учетом допустимых нормативных отклонений по РД 08-95-95.

Таблица 1. Краткая характеристика объекта исследования

Table 1. Brief description of the object of study

\begin{tabular}{|c|c|}
\hline $\begin{array}{l}\text { Параметр резервуара } \\
\text { Tank parameter }\end{array}$ & $\begin{array}{c}\text { Параметр согласно проектной } \\
\text { документации } \\
\text { Parameter according to design } \\
\text { documentation } \\
\end{array}$ \\
\hline $\begin{array}{l}\text { Тип резервуара } \\
\text { Tank type }\end{array}$ & $\begin{array}{l}\text { стальной вертикальный ци- } \\
\text { линдрический резервуар } \\
\text { steel vertical cylindrical tank }\end{array}$ \\
\hline $\begin{array}{l}\text { Номинальный объем, }{ }^{3} \\
\text { Nominal volume, } \mathrm{m}^{3}\end{array}$ & 10000 \\
\hline $\begin{array}{l}\text { Полезный объем, }{ }^{3} \\
\text { Useful volume, } \mathrm{m}^{3}\end{array}$ & 10105 \\
\hline $\begin{array}{l}\text { Диаметр, м } \\
\text { Diameter, } \mathrm{m}\end{array}$ & 34,2 \\
\hline $\begin{array}{l}\text { Высота стенки, м } \\
\text { Wall height, } \mathrm{m}\end{array}$ & 11,92 \\
\hline $\begin{array}{l}\text { Наименование продукта } \\
\text { Product name }\end{array}$ & $\begin{array}{c}\text { товарная и некондиционная } \\
\text { нефть } \\
\text { commercial and substandard oil }\end{array}$ \\
\hline $\begin{array}{l}\text { Марка стали листов } \\
\text { Steel grade sheets }\end{array}$ & $\begin{array}{l}09 \Gamma 2 \mathrm{C} \\
09 \mathrm{G} 2 \mathrm{~S} \\
\end{array}$ \\
\hline $\begin{array}{l}\text { Толщина листов стенок, мм } \\
\text { Thickness of the sheets of } \\
\text { walls, mm } \\
1 \text { пояс/1 zone } \\
2-8 \text { пояс } / 2-8 \text { zone }\end{array}$ & $\begin{array}{l}14,0 \\
12,0\end{array}$ \\
\hline $\begin{array}{l}\text { Толщина листов кровли, мм } \\
\text { Thickness of the roof sheets, } \\
\text { mm }\end{array}$ & 6,0 \\
\hline $\begin{array}{l}\text { Конструкция днища } \\
\text { Bottom construction }\end{array}$ & $\begin{array}{c}\text { полистовая сборка } \\
\text { sheet assembly }\end{array}$ \\
\hline $\begin{array}{l}\text { Конструкция крыши } \\
\text { Roof construction }\end{array}$ & $\begin{array}{l}\text { рулонная сборка } \\
\text { roll assembly }\end{array}$ \\
\hline $\begin{array}{l}\text { Место установки } \\
\text { Installation location }\end{array}$ & $\begin{array}{c}\text { Сузунское месторождение } \\
\text { Suzunskoe field }\end{array}$ \\
\hline $\begin{array}{l}\text { Нормативный срок эксплуа- } \\
\text { тации резервуара, лет } \\
\text { Standard tank life, years }\end{array}$ & 25 \\
\hline
\end{tabular}

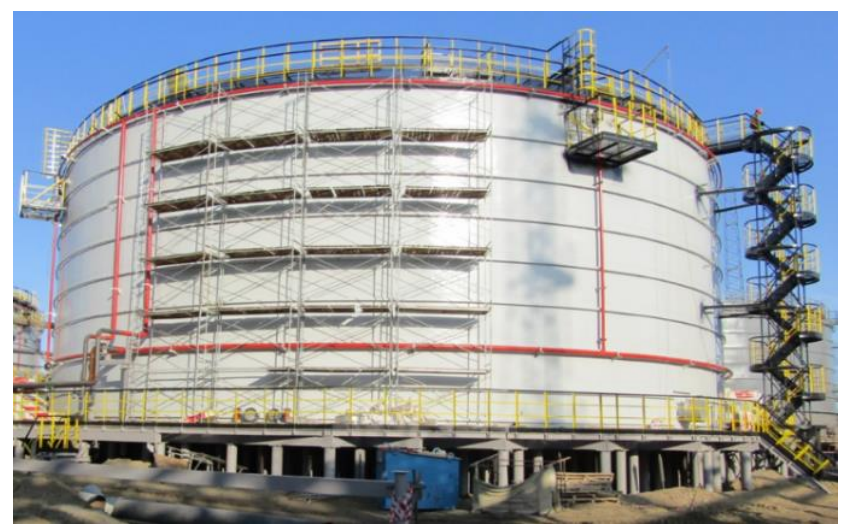

a/a

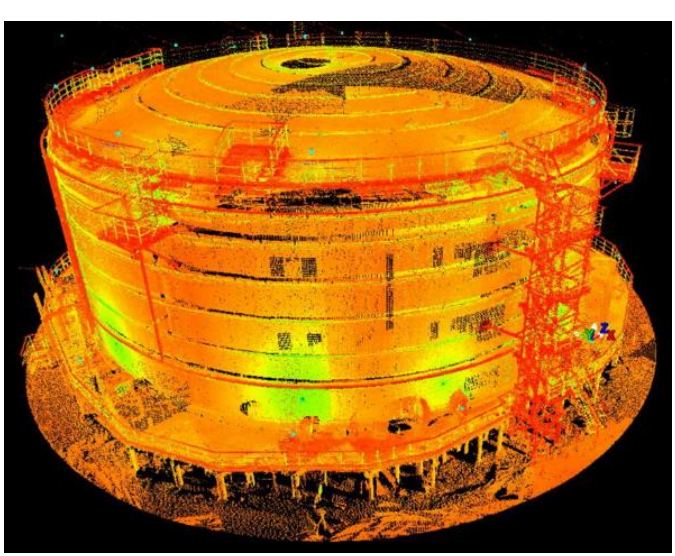

$\sigma / b$

Pис. 2. РВС: а) вид, б) материаль наземного лазерного сканирования в виде облак точек

Fig. 2. TVS: a) view, b) laser scanning result - point cloud 
Сегментирование облака точек. Для получения «чистого» облака точек стенок резервуара была проведена сегментация облака. Сегментированию подлежали попавшие в сектор сканирования предметы (в частности - внешнее оборудование, лестницы), не принадлежащие поверхности стенки резервуара. Эти объекты удалялись с помощью соответствующих инструментов в программе Leica Cyclone Register.

Определение зон деформации стенок резервуара. Для определения зон деформации резервуара по полученному облаку точек была построена триангуляционная модель. По основанию полученной модели было построено горизонтальное сечение и спроецировано на горизонтальную плоскость. В полученную проекцию была вписана окружность и выдавлена вдоль оси из центра окружности вдоль всей высоты резервуара.

На полученную модель цилиндра накладывается триангуляционная модель резервуара. Отклонения определяются между этими двумя поверхностями.

Полученные данные были представлены в отчётах двух видов.

Сечение идеальной и фактической поверхностей по поясам. Зоны несоответствия двух поверхностей раскрашиваются в соответствии с цветовой картой, диапазон отклонений между идеальной поверхностью и фактической для каждого цвета настраивается исполнителем. По результатам контроля выявлены отклонения от вертикали, образующие стенки сооружения, превышающие предельные значения, в соответствии с требованиями РД 08-95-95.

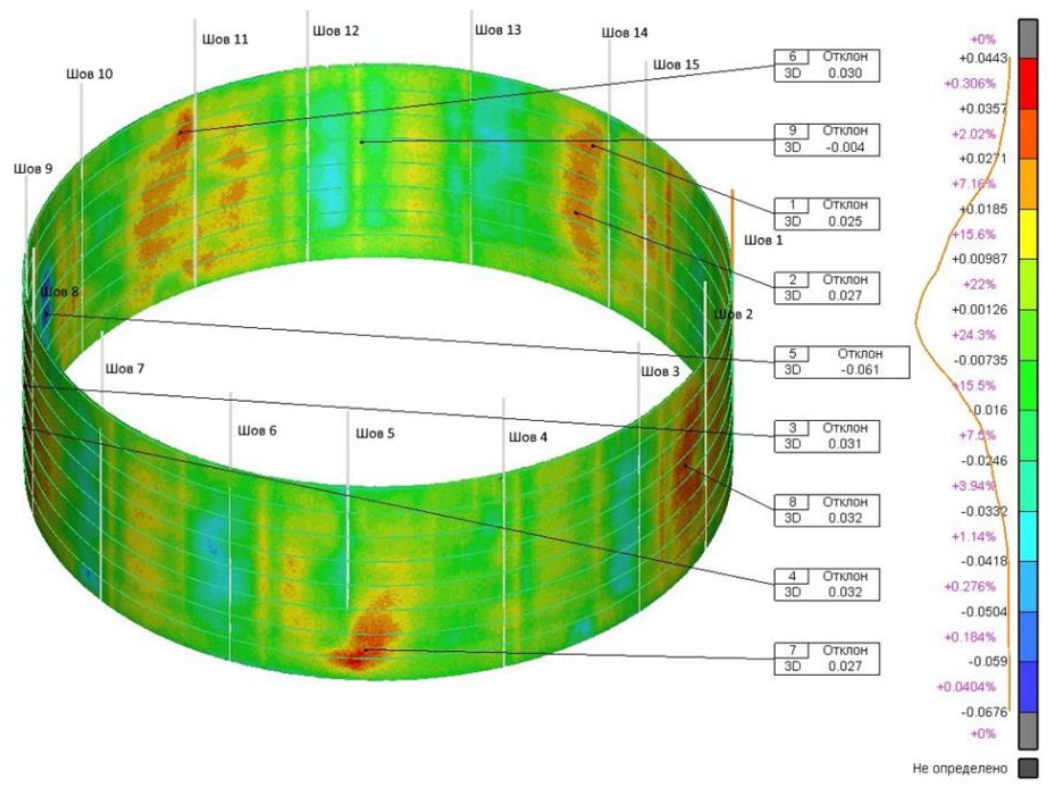

Рис. 3. Цветовая карта отклонений между идеальной поверхностью и фактической Fig. 3. Color map of deviations between ideal surface and actual
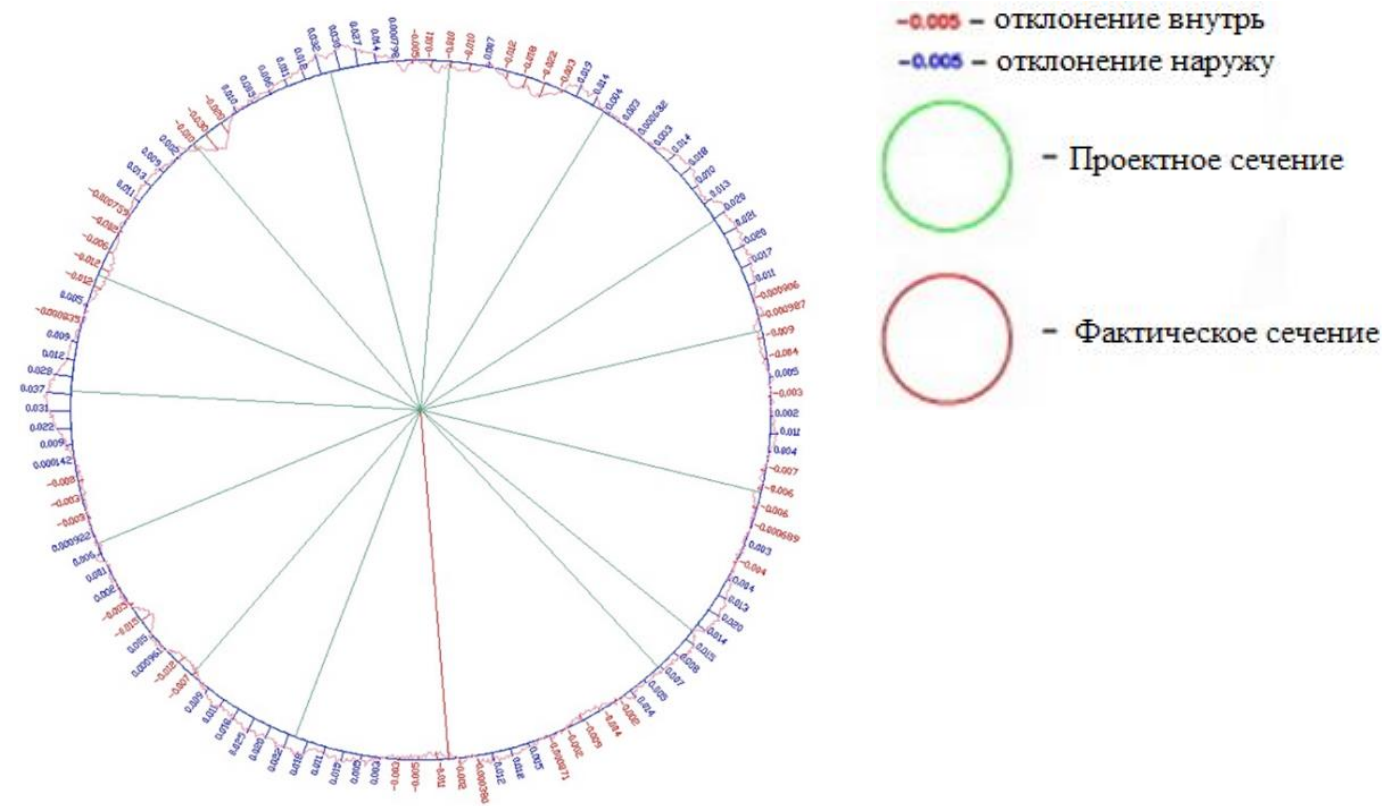

Рис. 4. Определение величин горизонтальных сечений от идеального изилиндра

Fig. 4. Determination of horizontal cross-sections from an ideal cylinder 
Определение величины отклонения образующих стенок РВС от вертикали. Для определения величины отклонения образующих стенок РВС от вертикали использовалась специальное программное обеспечение 3D Reshaper, которое позволило автоматизировать вычисления. Вычисление выполнялись с учетом всего множества измеренных точек, что повысило точность определения по сравнению с точностью единичного измерения. Результаты оформлены в форме графиков и таблиц с указанием допустимых величин отклонений и номера шва, по которому были выполнены вычисления.

Таблица 2. Анализ отклонений стенок резервуара

Table 2. Tank wall deviation analysis

\begin{tabular}{|c|c|c|c|c|c|c|c|c|c|c|c|c|}
\hline \multicolumn{3}{|c|}{ Базовое/Base } & \multicolumn{3}{|c|}{ Измерение/Unit } & \multicolumn{3}{|c|}{ Отклонение/Deviation } & \multirow[b]{2}{*}{ 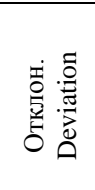 } & \multirow{2}{*}{ 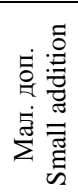 } & \multirow{2}{*}{ 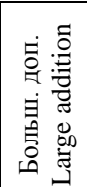 } & \multirow[b]{2}{*}{$\begin{array}{c}\text { Приращение } \\
\text { Increment }\end{array}$} \\
\hline $\mathrm{X}$ & $\mathrm{Y}$ & $\mathrm{Z}$ & $\mathrm{X}$ & $\mathrm{Y}$ & $\mathrm{Z}$ & $\mathrm{X}$ & $\mathrm{Y}$ & $\mathrm{Z}$ & & & & \\
\hline$-51,341$ & 17,629 & 7,859 & $-51,320$ & 17,614 & 7,859 & 0,02 & $-0,015$ & 0,000 & 0,025 & & & ++++ \\
\hline$-50,756$ & 18,487 & 3,385 & $-50,733$ & 18,473 & 3,385 & 0,023 & $-0,014$ & 0,000 & 0,027 & & & ++++ \\
\hline$-67,542$ & 44,528 & 4,869 & $-67,546$ & 44,559 & 4,869 & $-0,004$ & 0,031 & $-0,000$ & 0,031 & & & ++++ \\
\hline$-67,402$ & 44,542 & 2,240 & $-67,406$ & 44,573 & 2,240 & $-0,004$ & 0,031 & $-0,000$ & 0,032 & & & ++++ \\
\hline$-59,975$ & 43,858 & 3,594 & $-59,994$ & 43,800 & 3,594 & $-0,019$ & $-0,058$ & 0,000 & $-0,061$ & 0,036 & $-0,059$ & $-0,002 !$ \\
\hline$-51,346$ & 37,575 & 8,185 & $-51,322$ & 37,592 & 8,185 & 0,024 & 0,017 & $-0,000$ & 0,030 & & & ++++ \\
\hline$-82,317$ & 27,671 & 0,428 & $-82,344$ & 27,671 & 0,427 & $-0,027$ & 0,000 & $-0,000$ & 0,027 & & & +++++ \\
\hline$-73,399$ & 12,580 & 5,182 & $-73,414$ & 12,552 & 5,182 & $-0,015$ & $-0,028$ & 0,000 & 0,032 & & & ++++ \\
\hline$-48,182$ & 28,899 & 5,517 & $-48,185$ & 28,898 & 5,517 & $-0,004$ & $-0,000$ & $-0,000$ & $-0,004$ & & & + \\
\hline
\end{tabular}

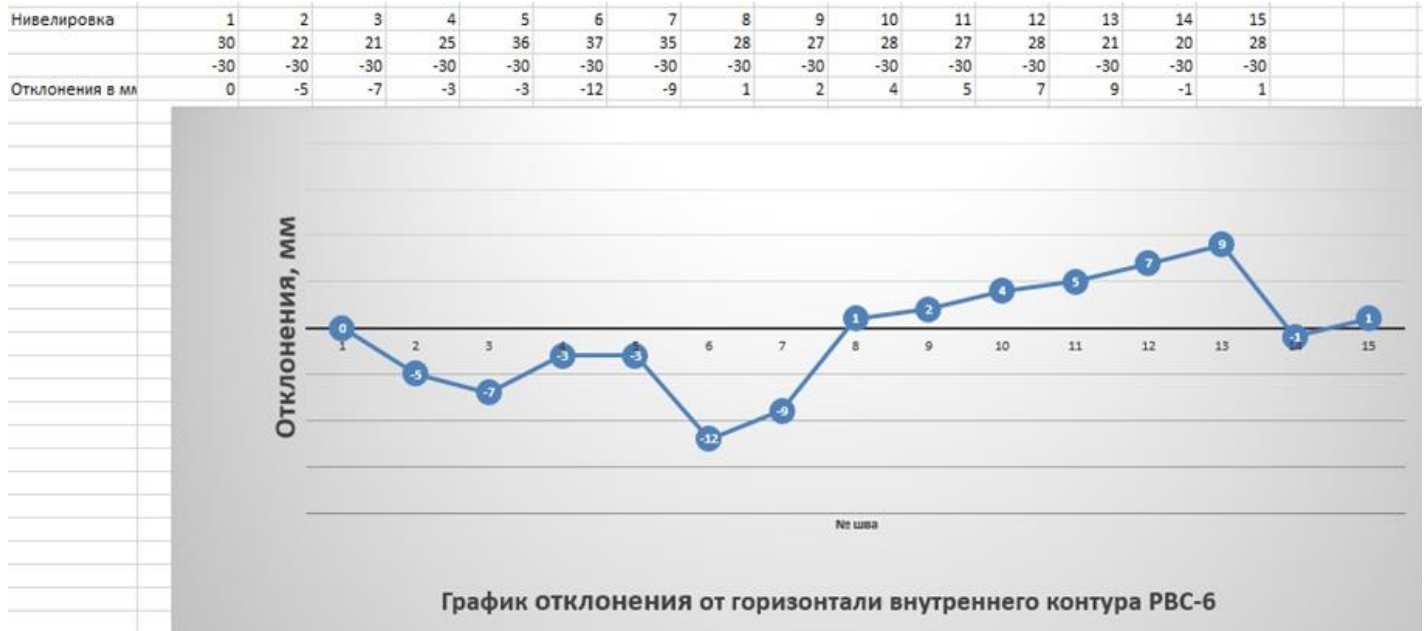

Рис. 5. График отклонения от горизонтали днища резервуара

Fig. 5. Graph of deviation from the tank bottom horizontal

В результате выполненных исследований установлены следующие отклонения в изготовленных конструкциях от требований Руководства по безопасности вертикальных цилиндрических стальных резервуаров для нефти и нефтепродуктов: полотнище стенки имеет локальное отклонение от проектной формы; выявлены прямолинейные участки полотнищ длиной около 1,5 м; серповидность листов 1-го и 2-го поясов по всей длине полотнища размером 15 мм; вогнутость стенки по всей высоте 43 мм; серповидность листов 1-го и 2-го поясов по всей длине полотнища размером 20-25 мм; полотнище стенки имеет локальное отклонение от проектной формы в виде вогнутости размером 26-30 мм.

Определение напряженно-деформированного состояния элементов конструкции сооружения от действия веса нефтепродуктов

В работах [1-30], рассматривающих численное моделирование поведения грунтовых массивов в резуль- тате их взаимодействия с различными инженерными сооружениями (железнодорожный мост, метрополитен, подпорная стенка, магистральный трубопровод, историческое здание театра), освещены преимущества использования метода конечных элементов в составлении расчетных моделей при строительстве и реконструкции инженерных сооружений и предотвращении аварийных ситуаций при их эксплуатации.

Расчеты напряженно-деформированного состояния сооружения «Стальной вертикальный цилиндрический резервуар объемом $\mathrm{V}=10000 \mathrm{~m}^{3}$ для хранения товарной и некондиционной нефти, поз. 6.2» выполнены в программном комплексе ANSYS на базе метода конечных элементов.

Расчеты для случая зафиксированных вмятин по ГОСТР 52857.11-2007 «Сосуды и аппараты. Методы расчета на прочность. Метод расчета на прочность обечаек и днищ с учетом смещения кромок сварных соединений, угловатости и некруглости кромок» сов- 
пали с точностью 3 \% с расчетами по МКЭ. Все «неровности» и выпуклости геометрии листов сооружения получены на основе лазерного сканирования реального объекта.

Максимальные допускаемые напряжения определены в соответствии с требованиями ГОСТ Р 52857.1-2007 «Сосуды и аппараты. Методы расчета на прочность», ГОСТ Р 52857.11-2007 «Нормы проектирования Стальных вертикальных резервуаров для хранения нефти объемом 1000-50000 м РД 16.01-60.30.00-КТН-026-1-04» (Приложение $\mathrm{A}[\sigma]=193$ МПа, Приложение Д $\varphi=0,65$ ). Метод расчета на прочность обечаек и днищ с учетом смещения кромок сварных соединений, угловатости и некруглости кромок» (пункт 5.1.1) и составили

$\sigma_{\max } \leq 1,5 \varphi[\sigma]=1,5 \cdot 0.65 \cdot 193=188,17$ МПа.

Входные данные к расчету представлены в табл. 3.

Таблица 3. Входные данные к расчету

Table 3. Input to the calculation

\begin{tabular}{|c|c|}
\hline $\begin{array}{c}\text { Характеристика } \\
\text { Characteristic }\end{array}$ & $\begin{array}{c}\text { Значение } \\
\text { Value }\end{array}$ \\
\hline Марка стали/Steel grade & $\begin{array}{l}09 \Gamma 2 \mathrm{C} \\
09 \mathrm{G} 2 \mathrm{~S}\end{array}$ \\
\hline $\begin{array}{l}\text { Модуль упругости Юнга, МПа } \\
\text { Young's modulus of elasticity, MPa }\end{array}$ & $2,06^{*} 10^{5}$ \\
\hline Коэффициент Пуассона/Poisson's ratio & 0,3 \\
\hline $\begin{array}{l}\text { Ускорение свободного падения, м/ } \mathrm{c}^{2} \\
\text { Acceleration of gravity, } \mathrm{m} / \mathrm{s}^{2}\end{array}$ & 9,81 \\
\hline Высота взлива нефтепродукта, м/Oil spill height, m & 10,8 \\
\hline $\begin{array}{l}\text { Плотность нефтепродукта, кг/м }{ }^{3} \\
\text { Density of oil product, } \mathrm{kg} / \mathrm{m}^{3}\end{array}$ & 780 \\
\hline Толщина листов днища, мм/Thickness of bottom sheets, mm & 8,0 \\
\hline Толщина листов крыши, мм/Thickness of roof sheets, mm & 6,0 \\
\hline
\end{tabular}

Каждый вид прочностного расчета был разбит на три этапа: 1 - построение геометрии расчетной 3D модели с требуемыми начальными условиями, границами разбиения и сгущения сетки конечных элемен- тов, 2 - введение граничных условий и нагружений исходя из постановки задач решения, 3 - в итоге графического представления обрабатывание полученных результатов. С целью уменьшения требуемых расчетных элементов ненагруженные ресурсы конструкции (площадки, подъемные лестницы, трубы, ограждения и т. д.) в численной расчетной модели изменены присоединенными массами, эквивалентными массам указанных элементов. Рассматривались следующие нагружения резервуара: нагрузки от собственного веса конструкции резервуара, гидростатическое давление жидкости нефтепродукта.

Результаты расчета показали, что максимальные напряжения составляют 135 МПа (при допустимых напряжениях $=188,17 \mathrm{MПа).}$

На рис. 7 представлена картина распределения общих перемещений в листах резервуара. Из расчета видно, что величина общих перемещений не превышает 29 мм. В результате расчета необходимо получить значения перемещений листов поясов и картину их напряжений в радиальном направлении. Для этого в решении была введена дополнительная цилиндрическая система координат. Перемещение листов поясов в радиальном направлении не превышает 3 мм. Значения напряжений составили порядка 90 МПа. Общие деформации в металле поясов резервуара, рассчитанные по критерию Мизеса, - в пределах 2 мм.

\section{Выводы}

1. В процессе монтажа, по результатам геодезических измерений, в соответствии с исполнительными схемами, а также с руководством по безопасности вертикальных цилиндрических стальных резервуаров для нефти и нефтепродуктов отклонений от проекта не выявлено.

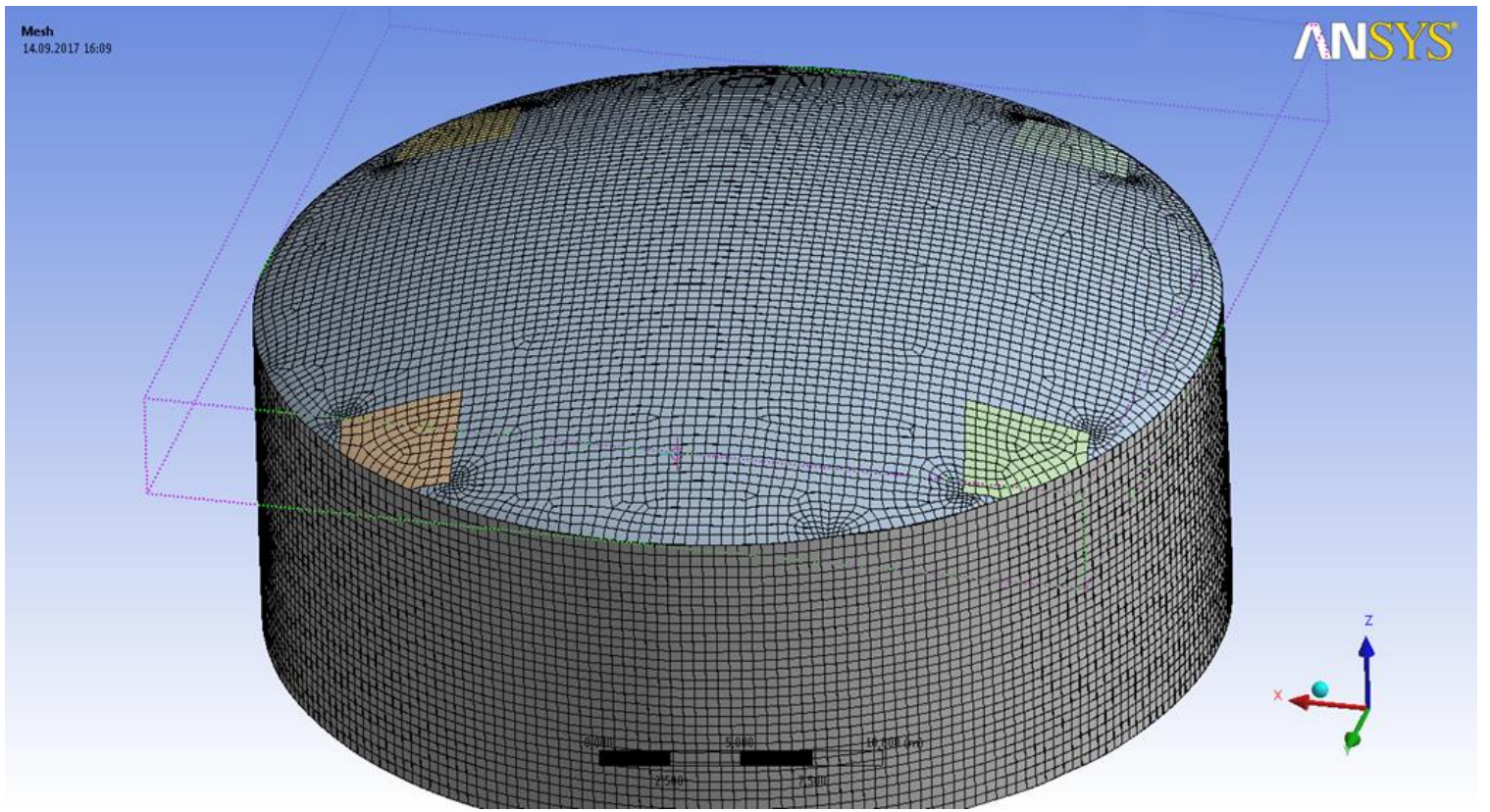

Puc. 6. Конечно-элементная модель резервуара

Fig. 6. Finite element model of the tank 


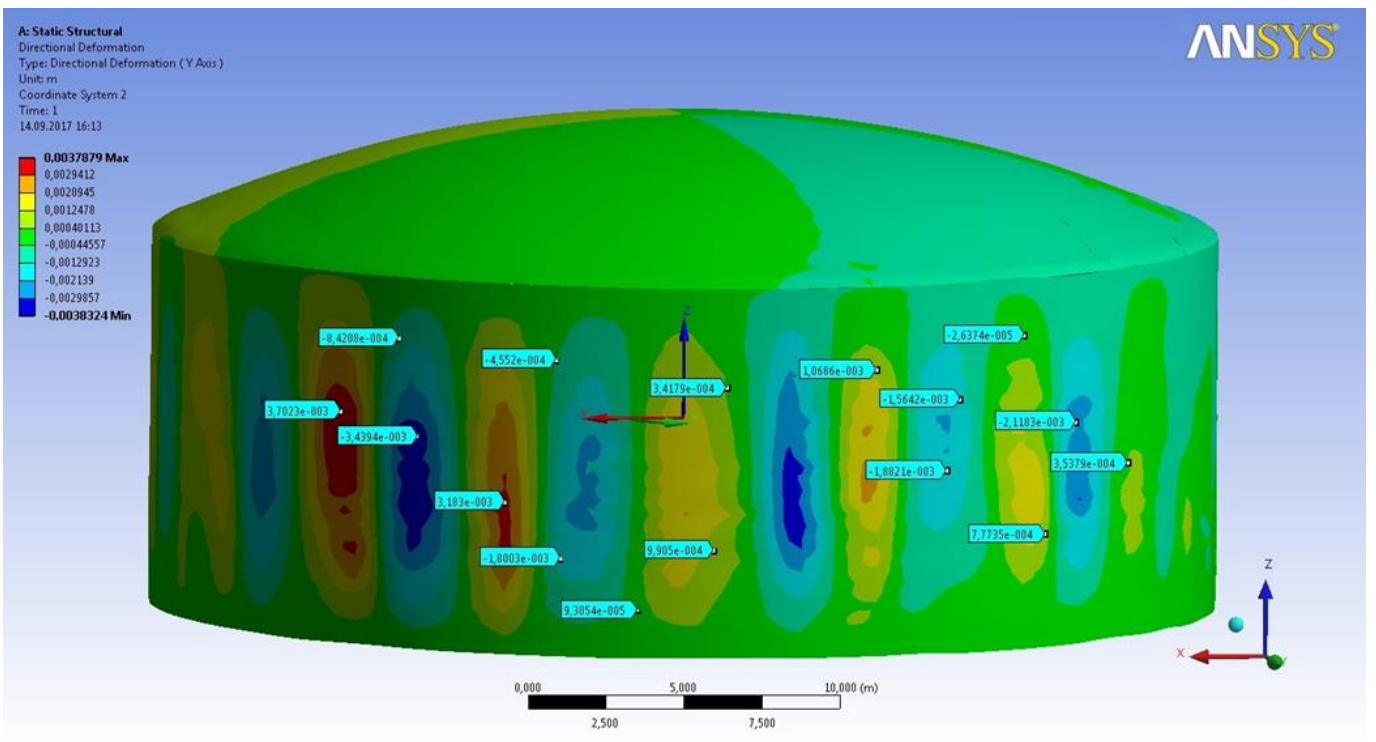

Рис. 7. Картина полей общих перемещений резервуара

Fig. 7. Picture of general displacement fields of the tank

2. По результатам проведенного наземного лазерного сканирования с внешней и внутренней сторон по полученным материалам сканирования обнаружены вертикальные отклонения стен сооружения, превышающие предельные значения, в соответствии с требованиями РД 08-95-95.

\section{СПИСОК ЛИТЕРАТУРЫ}

1. Светашков А.А., Куприянов Н.А., Манабаев К.К. Приближенный алгоритм решения задач линейной вязкоупругости // Вычислительная механика сплошных сред. - 2012. - Т. 5. № 3. - C. 292-299.

2. Перельмутер А.В., Сливкер В.И. Расчетные модели сооружений и возможность их анализа. - М.: ДМК Пресс, 2002. $618 \mathrm{c}$.

3. Field and laboratory studies on high-mast lighting towers in Iowa/ R.J. Connor, G. Callahan, M. Koob, I.C. Hodgson, B.L. Brakke / Proc. of the 2007 Mid-Continent Transportation Research Symposium. - Ames, Iowa, August 2007. - 16 p.

4. Static and dynamic flame model effects on thermal buckling: Fixed-roof tanks adjacent to an ethanol pool-fire / Y. Li, J. Jiang, Q. Zhang, (...), H. Liu, C.-M. Shu // Process Safety and Environmental Protection. - 2019. - V. 127. - P. 23-35.

5. Pantousa D., Godoy L.A. On the mechanics of thermal buckling of oil storage tanks // Thin-Walled Structures. - 2019. - V. 145. № 106432.

6. Failure analysis of a high mast lamp post / G. Das, S. Chakrabarty, A.K. Dutta, S.K. Das, K.K. Gupta, R.N. Ghosh // Engineering Failure Analysis. - 2006. - V. 13 (17). - P. 1153-1158.

7. Sherman R.J., Hebdon M., Connor R. Fatigue testing and retrofit details of high-mast lighting towers // Engineering Journal (American Institute of Steel Construction). - 2016. - V. 53 (1). P. 61-72.

8. Goode J.S., Van de Lindt J.W. Reliability-based design of medium mast lighting structural supports // Structure and Infrastructure Engineering. - 2013. - V. 9 (6). - P. 594-600.

9. Селезнева Е.В. Применение лазерного сканирования в геоморфологических исследованиях // Вестник МГУ. Сер. 5. 2013. - № 2. - C. 47-53.

10. Комиссаров А.В., Широкова Т.А., Комиссаров Д.В. Общий подход к изучению погрешностей наземной лазерной съемки, вызванных метрологическими свойствами объектов // Известия вузов. Геодезия и аэрофотосъемка. - 2013. - № 1. C. $36-42$.
3. По результатам расчета напряженно-деформированного состояния элементов сооружения в программном комплексе ANSYS установлено, что максимальные напряжения для элементов резервуара составляют 135 МПа при допустимых напряжениях 188,17 МПа; эксплуатация резервуара возможна на проектных параметрах.

11. Terrestrial laser scanning technology for deformation monitoring and surface modeling of arch structures / $\mathrm{H}$. Yang, M. Omidalizarandi, X. Xu, I. Neumann // Composite Structures. 2016. - V. 149. - P. 93-105.

12. Use of terrestrial laser scanning technology for long term high precision deformation monitoring / R. Vezočnik, T. Ambrožič, O. Sterle, G. Bilban, N. Pfeifer, B. Stopar // Sensors. - 2009. № 9. - P. 9873-9895.

13. Lichti D.D. A method to test differences between additional parameter sets with a case Photogrammetry and Remote Sensing // ISPRS Journal of Photogrammetry and Remote Sensing. - 2008. V. 63 (2). - P. 169-180.

14. Yang H., Xu X., Neumann I. Laser scanning-based updating of a finite element model for structural health monitoring // IEEE Sensor. - 2016. - V. 7. - P. 2100-2104

15. Terrestrial laser scanner for monitoring the deformations and the damages of buildings / G. Vacca, F. Mistretta, F. Stochino, A. Dessi // International Archives of the Photogrammetry, Remote Sensing \& Spatial Information Sciences. - 2016. - V. 41. Iss. B5. - P. 453-460.

16. Xu X., Yang H., Neumann I. Time-efficient filtering method for three-dimensional point clouds data of tunnel structures // Advances in Mechanical Engineering. - 2018. - V. 10 (5). - P. 1-6.

17. СП 43.13330.2012 Акт. ред. СНиП 2.01.03-85. Сооружение промышленных предприятий. - М.: Стандартинформ, 2012. $106 \mathrm{c}$.

18. СП 53-102-2004. Общие правила проектирования стальных конструкций/Госстрой России. - М.: ЦНИИСК им. Кучеренко, 2004. $-131 \mathrm{c}$

19. СП 20.13330.2016 Акт. ред. СНиП 2.01.07-85*. Нагрузки и воздействия. - М.: Стандартинформ, 2016. -104 с.

20. СП 16.13330.2011. Акт. ред. СНиП ІІ-23-81*. Стальные конструкции. Нормы проектирования. - М.: Стандартинформ, 2011. $-178 \mathrm{c}$.

21. Latypov A., Zharkova N., Nuriyev I. Landslide hazard assessment in city under construction Innopolis (Russia) // IOP Conference Series: Earth and Environmental Science. - 2016. - № 33. - 6 p. 
22. Ганова С.Д. Геоэкологические аспекты создания и функционирования природно-технических систем в условиях криолитозоны Западной Сибири // Известия высших учебных заведений. Геология и разведка. - 2017. - № 5. - С. 58-64.

23. Епифанова Е.А., Строкова Л.А. Оценка деформаций исторического здания в Томске с помощью комплексного подхода, основанного на сочетании наземного лазерного сканирования и конечно-элементного моделирования // Известия Томского политехнического университета. Инжиниринг георесурсов. 2018. - T. 329. - № 5. - C. 27-41.

24. Епифанова Е. А., Строкова Л.А. Анализ деформаций прожекторной мачты при помощи наземного лазерного сканирования и метода конечных элементов // Известия Томского политехнического университета. Инжиниринг георесурсов. 2019. - T. 330. - № 5. - C. 7-17.

25. Строкова Л.А., Ермолаева А.В. Природные особенности строительства участка газопровода «Сила Сибири» на участке Чаяндинское нефтегазоконденсатное месторождение - Ленск // Известия Томского политехнического университета. - 2015. № 4. - T. 326. - C. 41-55.

26. Строкова Л.А., Ермолаева А.В. Районирование территории по степени опасности оседания земной поверхности при проектировании магистрального газопровода в южной Якутии //
Известия Томского политехнического университета. Инжиниринг георесурсов. - 2016. - Т. 327. - № 10. - С. 59-68.

27. Строкова Л.А., Епифанова Е.А., Коржнева Т.Г. Численный анализ поведения основания опоры моста на старой железнодорожной линии // Известия Томского политехнического университета. Инжиниринг георесурсов. - 2017. - Т. 328. - № 5. C. $125-139$.

28. Strokova L.A., Teterin E. A. Identification, diagnosis and ranking of risks of geohazard in pipeline and urbanized territories // IOP Conference Series: Earth and Environmental Science. - 2016. V. 43. -6 p.

29. Purgina D.V., Strokova L.A., Kuzevanov K.I. Modeling of changing hydrogeological conditions during construction of pier foundations on the Kama river bank // IOP Conference Series: Earth and Environmental Science. - 2016. - V. 33. - 6 p.

30. Численное моделирование влияния упрочнения грунтового массива цементно-песчаной инъекцией на деформации основания / Л.А. Строкова, С.С.Т. Тарек, В.В. Голубева, В. Иванов // Известия Томского политехнического университета. Инжиниринг георесурсов. - 2017. - Т. 328. - № 10. - С. 6-17.

Поступила: 09.04.2020 2.

\section{Информация об авторах}

Enuфанова E.A., кандидат геолого-минералогических наук, инженер, Инженерная школа новых производственных технологий Национального исследовательского Томского политехнического университета. 
UDC 624.953

\title{
DEFINITION OF DEFORMATIONS OF STEEL VERTICAL CYLINDRICAL RESERVOIR WITH VOLUME OF V=10000 $\mathrm{M}^{3}$ FOR OIL USING TERRESTRIAL LASER SCANNING
}

\author{
Ekaterina A. Epifanova, \\ epifanovaea@tpu.ru \\ National Research Tomsk Polytechnic University, \\ 30, Lenin avenue, Tomsk, 634050, Russia.
}

The relevance of the topic is caused by the need to develop new approaches to assessing and forecasting structural changes in the space of critical engineering structures. The solution to this problem is associated with a large number of uncertain factors, such as incomplete laboratory data on the properties of materials, as well as field dynamic and static tests of such structures, lack of analytical information and monitoring studies. The article analyzes the results of field studies of deformations of a steel vertical cylindrical tank with a volume of $V=10000 \mathrm{~m}^{3}$ for storage of salable and substandard oil and compares it with a numerical analysis of its stress-strain state.

The purpose of the study is to analyze the data on the actual deformation of the object obtained as a result of terrestrial laser scanning, and assess its stress-strain state.

The object of the study is the change in the stress-strain state of a steel vertical tank with a volume of $V=10000 \mathrm{~m}^{3}$ for storage of salable and substandard oil located on the site of the oil treatment facility and gas turbine power plant of the Suzunskoe field of LLC RN-Vankor.

Methods. The initial data for modeling the behavior of the structure were materials of terrestrial laser scanning of the examined area. The stress-strain state of the structure was investigated using a software package based on the finite element method. Laser scanning technology was used to assess changes in the spatial-coordinate position and construct an accurate 3D model of the observation object. The object was scanned with a Leica Scanstation C10 terrestrial laser scanner, then the point cloud was processed in the Leica Cyclone 8.0 software package, the determination of the reservoir deformations was carried out in the 3D Reshaper software, ANSYS was used to analyze the stress-strain state of the object under study.

The results. The stress-strain state of the reservoir is estimated. A digital calculation model was created. The simulation results are compared with the position of the structures in the space obtained by laser scanning.

\section{Key words:}

Laser scanning, modeling, deformation, stress-strain state, finite element method.

\section{REFERENCES}

1. Svetashkov A. A., Kupriyanov N. A., Manabaev K. K. An approx imate algorithm for solving the problems of linear viscoelasticity. Computational continuum mechanics, 2012, vol. 5, no. 3, pp. 292-299. In Rus.

2. Perelmuter A.V., Slivker V.I. Raschetnye modeli sooruzheniy $i$ vozmozhnost ikh analiza [Calculation models of structures and possibilities of their analysis]. Moscow, DMK Press Publ., 2002, 618 p. In Rus.

3. Connor R.J., Callahan G., Koob M., Hodgson I.C., Brakke B.L. Field and Laboratory Studies on high-mast lighting towers in Iowa Proc. of the 2007 Mid-Continent Transportation Research Symposium. Ames, Iowa, August 2007. $16 \mathrm{p}$

4. Li Y., Jiang J., Zhang Q., Liu H., Shu C.-M. Static and dynamic flame model effects on thermal buckling: fixed-roof tanks adjacent to an ethanol pool-fire. Process Safety and Environmental Protection, 2019, vol. 127, pp. 23-35.

5. Pantousa D., Godoy L.A. On the mechanics of thermal buckling of oil storage tanks. Thin-Walled Structures, 2019, vol. 145, no. 106432 .

6. Das G., Chakrabarty S., Dutta A.K., Das S.K., Gupta K.K., Ghosh R.N. Failure analysis of a high mast lamp post. Engineering Failure Analysis, 2006, vol. 13 (17), pp. 1153-1158.

7. Sherman R.J., Hebdon M., Connor R. Fatigue testing and retrofit details of high-mast lighting towers. Engineering Journal (American Institute of Steel Construction), 2016, vol. 53 (1), pp. 61-72.

8. Goode J.S., Van de Lindt J.W. Reliability-based design of medium mast lighting structural supports. J. Structure and Infrastructure Engineering, 2007, vol. 9, no. 6, pp. 594-600.

9. Selezneva E.V. Application of laser scanning in geomorphologic studies. MSU Vestnik. Series 5, 2013, vol. 2, pp. 47-53. In Rus.

10. Komissarov A.V., Shirokova T.A., Komissarov D V. The general approach to the study of errors of terrestrial laser shooting caused by metrological properties of objects. Izvestija vuzov. Geodesy and aerophotosurveying, 2013, no. 1, pp. 36-42. In Rus.

11. Yang H., Omidalizarandi M., Xu. X., Neumann I. Terrestrial laser scanning technology for deformation monitoring and surface mod- eling of arch structures. Composite Structures, 2016, vol. 149, pp. 93-105.

12. Vezočnik R., Ambrožič T., Sterle O., Bilban G., Pfeifer N., Stopar B. Use of terrestrial laser scanning technology for long term high precision deformation monitoring. Sensors, 2009, no. 9, pp. 9873-9895.

13. Lichti D.D. A method to test differences between additional parameter sets with a case study in terrestrial laser scanner selfcalibration stability analysis. ISPRS Journal of Photogrammetry and Remote Sensing, 2008, vol. 63, no. 2, pp. 169-180.

14. Yang H., Xu X., Neumann I. Laser scanning-based updating of a finite element model for structural health monitoring. IEEE Sensor, 2016, no. 7, pp. 2100-2104.

15. Vacca G., Mistretta F., Stochino F., Dessi A. Terrestrial laser scanner for monitoring the deformations and the damages of buildings. International Archives of the Photogrammetry, Remote Sensing \& Spatial Information Sciences, 2016, vol. 41, Iss. B5, pp. 453-460.

16. Xu X., Yang H., Neumann I. Time-efficient filtering method for three-dimensional point clouds data of tunnel structures. Advances in Mechanical Engineering, 2018, vol. 10 (5), pp. 1-6.

17. SP 43.13330.2012 Act. ed. SNiP 2.01.03-85. Sooruzhenie promyshlennykh predpriyatiy. [The construction of industrial enterprises]. Moscow, Standartinform Publ., 2012. 106 p.

18. SP 53-102-2004. Obshchie pravila proektirovaniya stalnykh konstruktsiy [General rules for the design of steel structures]. Moscow, TSNIISK im. Kucherenko Publ., 2004. 131 p.

19. SP 20.13330.2016 Act. ed. SNiP 2.01.07-85*. Nagruzki $i$ vozdeystviya [Loads and impacts]. Moscow, Standartinform Publ., 2016. $104 \mathrm{p}$

20. SP 16.13330.2011. Act. ed. SNiP II-23-81*. Stalnye konstruktsii. Normy proyektirovaniya [Steel structures. Design Standards]. Moscow, Standartinform Publ., 2011. 178 p.

21. Latypov A., Zharkova N., Nuriyev I. Landslide hazard assessment in city under construction Innopolis (Russia). IOP Conference Series: Earth and Environmental Science, 2016, vol. 33, 6 p.

22. Ganova S.D. Geoecological aspects of the creation and functioning of the natural- technical systems under the conditions of the of 
Western Siberia cryolithic zone. Proceedings of Higher Schools. Geology and exploration, 2017, vol. 5, pp. 58-64. In Rus.

23. Epifanova E.A., Strokova L.A. Evaluation of deformation of a historic building in Tomsk by an integrated approach based on Terrestrial Laser Scanner and Finite Element Modeling. Bulletin of the Tomsk Polytechnic University. Geo Assets Engineering, 2018, vol. 329 , no. 5, pp. 27-41. In Rus.

24. Epifanova E.A., Strokova L.A. Numerical analysis of deformation of the lighting mast by ground laser scanner and finite elemen method. Bulletin of the Tomsk Polytechnic University. Geo Assets Engineering, 2019, vol. 330, no. 5, pp. 7-17. In Rus.

25. Strokova L.A., Ermolaeva A.V. Natural features of construction of the main gas pipeline «The Power of Siberia» on a site Chayandinskoe oil and gas field - Lensk. Bulletin of the Tomsk Polytechnic University, 2015, vol. 326, no. 4, pp. 41-55. In Rus.

26. Strokova L.A., Ermolaeva A.V. Zoning according to the hazard level of earth surface subsidence when designing the main gas pipeline in south Yakutia. Bulletin of the Tomsk Polytechnic University. Geo Assets Engineering, 2016, vol. 327, no. 10, pp. 59-68. In Rus.
27. Strokova L.A., Epifanova E.A., Korzhneva T.G. Numerical analysis of bridge foundation behaviour on the old railway line. Bulletin of the Tomsk Polytechnic University. Geo Assets Engineering, 2017, vol. 328, no. 5, pp. 125-139. In Rus.

28. Strokova L.A., Teterin E. A. Identification, diagnosis and ranking of risks of geohazard in pipeline and urbanized territories. IOP Conference Series: Earth and Environmental Science. 2016, Vol. 43, 012051

29. Purgina D.V., Strokova L.A., Kuzevanov K.I. Modeling of changing hydrogeological conditions during construction of pier foundations on the Kama river bank. IOP Conference Series: Earth and Environmental Science, 2016, vol. 33, 01246.

30. Strokova L.A., Tarek S.S.T., Golubeva V.V., Ivanov V. Numerical modeling of influence of soil mass reinforcement with cementsand grouting on foundation deformation. Bulletin of the Tomsk Polytechnic University. Geo Assets Engineering, 2017, vol. 328, no. 10, pp. 6-17. In Rus.

Received: 9 April 2020.

\section{Information about the authors}

Ekaterina A. Epifanova, Cand. Sc., engineer, National Research Tomsk Polytechnic University. 